\title{
Fostering entrepreneurship in an international university collaboration
}

\author{
Rybnicek, Robert ${ }^{\mathrm{a}}$; Gutschelhofer, Alfred ${ }^{\mathrm{a}}$; Bergner, Sabine ${ }^{\mathrm{a}}$; Seidenberger, \\ Alexander ${ }^{\mathrm{a}}$ and Taferner, Remo ${ }^{\mathrm{a}}$ \\ ${ }^{a}$ Department of Corporate Leadership and Entrepreneurship, University of Graz, Austria.
}

\begin{abstract}
The European Union is taking action on enhancing entrepreneurship in Europe and recommends appropriate entrepreneurship training in schools and higher education institutions. Due to the globalization of businesses it seems to be appropriate to realize an international perspective on entrepreneurial issues and to develop international programmes for young entrepreneurs. In this case study, we examined an international university collaboration between two universities, one in Austria and one in the United States. The programme's goals include the establishment of an international network for students and an awareness of the students of different cultural dimensions and entrepreneurial mindsets. Our findings show how this programme enables the students to work on their professional and behavioural skills, how these students work practice-oriented under the guidelines of experts from different entrepreneurial mindsets and how they become aware of cultural differences. Besides other aspects, it seems to be advantageous for international entrepreneurship programmes to remain open and flexible during the whole process and to offer a programme that allows students to integrate participation into their regular studies. Furthermore, it seems beneficial that students can tailor the programme to meet their specific needs.
\end{abstract}

Keywords: entrepreneurship education, collaboration, mobility, internationalization 


\section{Introduction}

In response to the growing importance of small businesses and start-ups, the European Union seeks to enhance entrepreneurship within Europe in order to develop awareness of this career path from primary school to university (European Commission, 2006). As a consequence of these efforts, entrepreneurship education programmes became a part of many higher education institutions and several regions tried to build fruitful entrepreneurship ecosystems to foster the local start-up scene. But with respect to the intense competition in international markets, small and medium-sized enterprises often face special challenges (Etemad, 2004). Therefore, it seems reasonable that young companies and their founders should know about cultural differences, foreign ecosystems and diverse entrepreneurial perspectives and approaches in order to increase their chances of a successful implementation of their business idea.

In the course of this paper, we examine an international entrepreneurship programme that takes place in the United States and in Austria. In this case study we investigate and discuss the most important factors regarding the objectives, implementation and content of this programme. This article is aimed at teachers and researchers in the field of entrepreneurship education to provide an insight into international programmes and student mobility to inspire similar programmes in the future. It is considered to share important lessons learned and suggest further fields of development for entrepreneurship student exchanges.

In the following section we provide a very short overview of entrepreneurship education, before we describe our case study. Afterwards we discuss our results in the light of the analysed literature and draw some conclusions for the development of international entrepreneurship programmes.

\section{Theoretical background}

There is a consensus that entrepreneurship can be taught, and there is evidence that entrepreneurial attributes can be positively influenced by entrepreneurship education (Gorman, Hanlon, \& King, 1997). This impacts students' awareness of entrepreneurship as an alternative career path to employment and provides them with skills needed to start and successfully run their businesses (Gorman et al., 1997; Slavtchev, Laspita, \& Patzelt, 2012). The literature emphasizes different key aspects in entrepreneurship education, for example:

Professional skills. Entrepreneurship education should provide basic skills in traditional business disciplines, e.g. management, marketing, controlling, finance and accounting to enable students to manage a company (Jones \& English, 2004). Being aware of the basics of the market environment and insights into economics can complement this knowledge to 
assess business ideas and their chances. Many authors propose a mixture of professional competences and soft skills (Plaschka \& Welsch, 1990; Vesper \& McMullan, 1988).

Behavioural and attitudinal competencies. This category covers all aspects of soft skills, such as personality traits, communication, language, personal habits and social manners, as well as competences that are more entrepreneurship-specific, like opportunity recognition and assessment, negotiation, leadership, risk management, commercializing, creativity and creative thinking, marshalling resources, focusing, self-efficacy and networking (e.g. Jones \& English, 2004; Morris, Webb, Fu, \& Singhal, 2013; Plaschka \& Welsch, 1990; Vesper \& McMullan, 1988).

Practice. The literature often states the relevance of learning-by-doing activities in a group setting or network context (e.g. Rasmussen \& Sørheim, 2006). Practice-orientated activities, such as working in start-ups or starting businesses as coursework, writing business plans, meeting entrepreneurs, simulations, videos of new venture start-ups, role play and business games play another important role (e.g. Clouse, 1990; Vesper \& McMullan, 1988).

Awareness and self-assessment. Entrepreneurship education should enable students to discover their specific abilities and inform them about alternative career options that might be suitable for them (Graevenitz, Harhoff, \& Weber, 2010). Through such courses students acquire a more realistic perspective on what it takes to become an entrepreneur, which can result in undecided students either enhancing or abandoning their ambitions to start their own business (Oosterbeek, van Praag, \& Ijsselstein, 2010; Slavtchev et al., 2012).

\section{Case study}

In this section we analyze the international programme and the situation at the investigated universities and elaborate the most important factors regarding objectives, implementation and content. The locations in this case study are in the United States and in Austria. The former one has about 38,000 residents and 21,000 students and is located next to one of the largest entrepreneurial ecosystems in the United States. The latter one has about 290,000 residents and 60,000 students and has a steady growing entrepreneurial community. The situation on both locations is characterized by different study rules, very dissimilar mindsets regarding the affinity towards entrepreneurship as a possible way to create one's own future, and a different cultural attitude towards failure.

\subsection{Objectives of the programme}

The universities in this programme established an extensive exchange programme first and foremost to open the students' minds to different approaches towards entrepreneurship, to enable insights into different entrepreneurial ecosystems and to connect students from 
different backgrounds and life realities with each other to build friendships and business relationships. The programme provides essential basics about entrepreneurship in different environments to increase the general understanding of entrepreneurial cultures and to promote intercultural thinking and acting. Students should acquire a theoretical and - very importantly - a practical understanding of what it takes to found a company in the two countries. The outcome of the programme should result in intensified relations between the two continents. Students learn from each other and furthermore they see and feel the different perspectives of both mindsets and realities. Moreover, they study the two different business locations and their advantages and disadvantages. The collaboration therefore comprises the following goals:

- To initiate an international partnership between universities in Austria and the US.

- To establish an international network of entrepreneurs between the two regions.

- To enhance the visibility and reputation of both (entrepreneurial) regions.

- To sensitize students from both universities to the topic of entrepreneurship.

- To sensitize students to the cultural dimensions of entrepreneurship.

- To familiarize students with two different entrepreneurial ecosystems.

- To create and understand different entrepreneurial mindsets among the students.

- To initiate entrepreneurial student projects.

- To inspire students to engage in entrepreneurial activities.

\subsection{Implementation of the programme}

In the programme's development phase, it was necessary to decide how profoundly the programme should be integrated into existing study curricula. It was decided to integrate it by granting ECTS credits for all participating Austrian students and academic credits for the students from the United States. These can be accounted for elective courses to the amount of five ECTS or three academic credits, so students can integrate the programme into their regular studies without 'losing' time. Furthermore, students can participate irrespective of their studies and academic progress. They can also acquire an 'International Entrepreneurship Certificate' to formally confirm qualifications for their further career.

Except for the cost of the flights, the programme is free of charge for the students and is funded by the entrepreneurship departments and the business faculties of the involved universities. Due to limited resources, the decision-making and funding processes only proceeded slowly during the development phase. For the US university in particular, it proved to be difficult acquiring such heavily supported funding, while the process in Austria progressed more quickly. 
The selection process of the students aimed at filtering not only the most qualified but also the most interested and motivated students to take part in the exchange. Both universities established an independent process to each select 20 students. Besides other criteria, the curriculum vitae, entrepreneurship and work experience, the motivation letter and a (potentially) concrete business idea were rated by five staff members to ensure an objective selection.

\subsection{Content of the programme}

The programme consists of four stages, which are depicted in Figure 1. Generally, the programme is designed interactively, so that students can perform much of the work on various questions independently, while being mentored by faculty staff and practitioners.

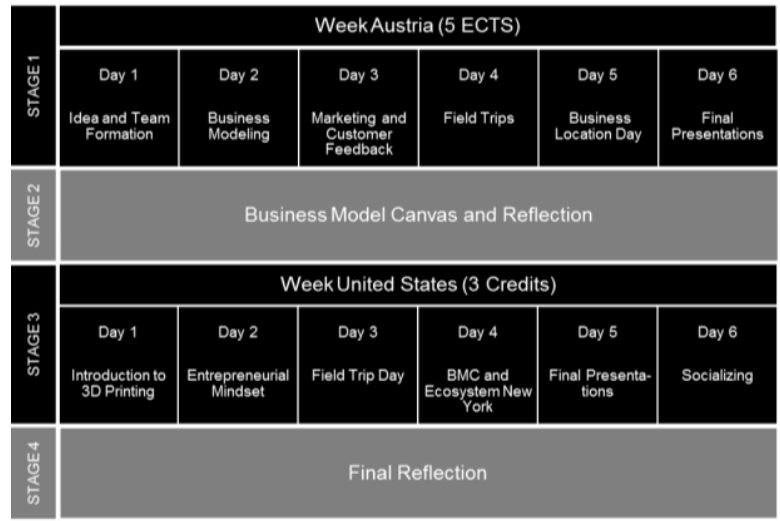

Figure 1. The Annual Transatlantic Entrepreneurship Academy. Source: Authors' illustration.

The first stage takes place at the Austrian university and lasts a week. In this week students receive a broad introduction to the differences in the entrepreneurship ecosystems and cultures. Activities will contain team building, idea generation and conception of start-up ideas as well as the preparation of the business model canvas. The week is organized in the form of a start-up camp, where students cooperatively work on their start-up ideas and pitch the outcomes. This is a very practical approach towards entrepreneurship, with a lot of hands-on tasks, creating a minimum viable product, collecting customer feedback and improving as well as iterating the products. Along with the practical sessions, students will hear from experts from real businesses as well as lecturers and professors all the theoretical background they should have. They further have to deal with very specific questions concerning the ecosystems specifics of both the United States and Europe. At the end of week one, students should have a basic knowledge of what it takes to found a company, 
should know about the main differences of the two business locations and should be able to pitch their start-up ideas in front of judges.

The second stage starts after week one in Austria and ends when the students go to the United States. In this stage the teams should work from home, should use the business model canvas, improve their ideas and work independently via social media, Skype and other tools. In addition, the students need to write a reflection about week one of the programme. Based on these reflections the third stage of the programme will be customized to the needs of these students.

The third stage will intensify the work on the start-up ideas, will work on 3D printing in order to create minimum viable products and will have a focus on the pitching skills as well as the entrepreneurial mindset that is needed for young entrepreneurs. At the beginning of the week in the United States, the business model canvas should be ready for evaluation. The content of this stage is deliberately variable and depends on the feedback and insights of stages one and two. Furthermore, both universities will reflect on the goals attained, as well as the good and bad outcomes of the previous stages. Apart from the flexible contents, this stage definitely involves implementation planning and the development of early prototypes, mainly in the form of 3D prints. At the end the ideas are pitched and students receive feedback from qualified judges who are also available for extensive Q\&A.

The fourth stage provides the opportunity for a final reflection about the experience and the lessons learnt by the students. Similarly to the second stage, students shall give the organizers feedback that will directly be used to improve the programme for the following year. To increase involvement it is furthermore planned that students participating in this year's programme will become project coordinators for the next year in order to guarantee its improvement by having those with first-hand experience working on it.

\section{Discussion}

According to our short literature review in section 2, entrepreneurship education should target different aspects. The programme meets these aspects in various ways:

Professional skills. The programme provides fundamental knowledge in creating, conceptualizing and developing an entrepreneurial idea. Students further learn to understand and apply the start-up management template, the business model canvas. The aim is to give students useful (management) tools for an upcoming start-up phase.

Behavioural and attitudinal competencies. The programme's international and intercultural approach opens the students' minds to another entrepreneurial ecosystem and offers the challenge to deal with it in a safe environment. They also improve their social 
abilities, especially when working in international teams, which involves occupying and distributing roles within the team, managing (cultural) conflicts and creating a sense of togetherness.

Practice. The whole programme provides a high level of practice orientation. Students work in interdisciplinary teams to develop their own business models. Workshops on storytelling and pitching, legal basics, design thinking, marketing, 3D printing, and ebusiness are included in the programme. The multi-professional mentors form a key part of the programme as they advise on practical issues such as marketing, sales, design or even financing and software development. Through individual and personal coachings, open questions are handled competently and quickly.

Awareness and self-assessment. This programme leads to a better political, economic and cultural awareness of entrepreneurship. Besides that, it is not limited to business students, ensuring that students of all disciplines can apply, participate and become aware of entrepreneurship as a possible career option. The programme enables them to better assess themselves and their business ideas. Students learn about their strengths and weaknesses and find out whether they are qualified as an entrepreneur or not.

\section{Conclusion}

In conclusion, this case study provides some interesting insights for the implementation of international entrepreneurship collaborations at universities:

First, it requires the partners to avoid imposing their own (cultural) rules and conventions on others. This counts for the content as well as for bureaucratic obstacles that occurred during the development and implementation of the programme as the number of people involved in such a project can get surprisingly high. It also required a considerable amount of workforce, which should be scheduled very carefully by the executing department.

Secondly, it seems to be advantageous to provide an interdisciplinary approach, which ensures that all students - and not only business students - can become aware of entrepreneurship as a career option. Students also seemed to benefit immensely from their manifold proficiencies. Moreover, it appeared to be beneficial that students could tailor the programme to meet their specific needs. Like the schedule for Stage 1, which was too tight for one week but was successfully adjusted for Stage 3 .

Thirdly, the flexible integration into regular academic studies has to be emphasized as today's students are often facing time or financial pressure. The integration into curricula through elective courses allowed the students to attend the programme without 'losing' time and the university sponsorship enabled participation without further financial risks. 


\section{References}

Clouse, V. G. H. (1990). A controlled experiment relating entrepreneurial education to students' start-up decisions. Journal of Small Business Management, 28(2), 45-53.

Etemad, H. (2004). Internationalization of small and medium-sized enterprises: A grounded theoretical framework and an overview. Canadian Journal of Administrative Sciences, 21(1), 1-21. doi:10.1111/j.1936-4490.2004.tb00319.x

European Commission. (2006). Implementing the Community Lisbon Programme: Fostering entrepreneurial mindsets through education and learning. Communication from the commission to the European parliament, the council, the European economic and social committee and the committee of the regions. Retrieved from European Commission website: http:/eur-lex.europa.eu/legalcontent/EN/TXT/PDF/?uri=CELEX:52006DC0033\&from=EN

Gorman, G., Hanlon, D., \& King, W. (1997). Some research perspectives on entrepreneurship education, enterprise education and education for small business management: A ten-year literature review. International Small Business Journal, 15(3), 56-77. doi:10.1177/0266242697153004

Graevenitz, G. von, Harhoff, D., \& Weber, R. (2010). The effects of entrepreneurship education. Journal of Economic Behavior \& Organization, 76(1), 90-112. doi:10.1016/j.jebo.2010.02.015

Jones, C., \& English, J. (2004). A contemporary approach to entrepreneurship education. Education + Training, 46(8/9), 416-423. doi:10.1108/00400910410569533

Morris, M. H., Webb, J. W., Fu, J., \& Singhal, S. (2013). A competency-based perspective on entrepreneurship education: Conceptual and empirical insights. Journal of Small Business Management, 51(3), 352-369. doi:10.1111/jsbm.12023

Oosterbeek, H., van Praag, M., \& Ijsselstein, A. (2010). The impact of entrepreneurship education on entrepreneurship skills and motivation. European Economic Review, 54(3), 442-454. doi:10.1016/j.euroecorev.2009.08.002

Plaschka, G. R., \& Welsch, H. P. (1990). Emerging structures in entrepreneurship education: Curricular designs and strategies. Entrepreneurship Theory and Practice, 14(3), 55-71.

Rasmussen, E. A., \& Sørheim, R. (2006). Action-based entrepreneurship education. Technovation, 26(2), 185-194. doi:10.1016/j.technovation.2005.06.012

Slavtchev, V., Laspita, S., \& Patzelt, H. (2012). Effects of entrepreneurship education at universities. Jena Economic Research Papers, 25, 1-33.

Vesper, K. H., \& McMullan, E. W. (1988). Entrepreneurship: Today courses, tomorrow degrees? Entrepreneurship Theory and Practice, 13(1), 7-13. 